\title{
Article
}

\section{Sorption Removal of Arsenic (V) by Sn-loaded Poly(hydroxamic) Acid Chelating Resin}

\author{
*Md Jelas Haron, Wan Md Zin Wan Yunus, W. C. Tan and Anuar Kassim \\ Chemistry Department, Faculty of Science, \\ Universiti Putra Malaysia, 43400 Serdang Selangor, Malaysia.
}

(Manuscript submitted March 25, 2007; accepted May 16, 2007)

\begin{abstract}
Sorption conditions of arsenate ions onto Sn-loaded poly(hydroxamic acid) chelating resin (Sn-PHA) have been studied. Sorption isotherms data correlated well to the Langmuir model with maximum capacity of $38.46 \mathrm{mg} \mathrm{g}^{-1}$ at $\mathrm{pH} 2$. Sorption process follows pseudo-second order kinetics. Intraparticle diffusion was found to take part in sorption processes. The free energy $(E)$ was $11.18 \mathrm{~kJ} \mathrm{~mol}^{-1}$ which shows the sorption is an ion-exchange process. Thermodynamic parameters, $\Delta H^{\circ}, \Delta S^{\circ}$ and $\Delta G^{\circ}$ were also calculated from the experimental data. Standard heat of sorption was found to be endothermic and entropy change value was calculated to be positive. Negative $\Delta G^{\circ}$ value indicates that the sorption process for the arsenic anions onto Sn-PHA is spontaneous.
\end{abstract}

Key words: Tin-poly(hydroxamic acid) resin, arsenic removal

\section{Introduction}

Environmental pollution of arsenic from industrial wastewater streams as a consequence of the industrialization process is one of the major problems that have to be solved or controlled. Many industrial activities such as mining, combustion of fossil fuels, and the production of glasses, nonferrous alloys, semiconductor materials, arsenic pesticides, herbicides and crop desiccants discharge arsenic and other heavy metals via their waste effluents [1,2]. Some of these metals, even in small amounts can cause severe physiological and health effects. Therefore, heavy metals including arsenic are permitted to be discharged only in a very low concentration in wastewaters to prevent public streams and water resources from becoming contaminated.

Methods for the removal of arsenic ion from waste streams include chemical precipitation, membrane filtration, ion exchange, carbon sorption and coprecipitation/adsorption. However conventional method such as precipitation does not always provide a satisfactory removal rate to meet the pollution control limits. Therefore many researches were carried out for effective alternative technologies or sorbents for treatment of arsenic from the waste streams resulted in search for unconventional methods and materials [3]

Recently hydrous tin oxide was found effective for sorption of arsenate ion [4]. However, the compounds dissolved significantly even in mild acidic $\mathrm{pH}$. In addition, a common drawback of inorganic ion exchangers is usually very fine and difficult to obtain in spherical beads of suitable size for the required applications. In order to overcome this difficulty, the oxide can be incorporated into the pores of a porous polymer resin [5]. Our previous data showed that poly(hydroxamic acid) chelating resin form stable complex with $\mathrm{Sn}(\mathrm{IV})$ [6]. In this study, the possibility of using tin-loaded poly(hydroxamic acid) chelating resin for removal of arsenate ions from an aqueous solution was investigated. Several parameters, which affect the arsenic removal are reported. These include the effect of $\mathrm{pH}$, initial arsenic concentrations, contact time, temperature and selectivity. From the experimental data the mechanism of removal was suggested. The resin was also tested for removal of arsenic from industrial wastewater samples.

\subsection{Materials}

\section{Experimental}

Tin (IV) stock solution was prepared by dissolving $\mathrm{SnCl}_{4}$ (Merck) in $0.1 \mathrm{M} \mathrm{HCl}(\mathrm{BDH})$ solution. Arsenic (V) stock solution was prepared from $\mathrm{Na}_{2} \mathrm{HAsO}_{4} .7 \mathrm{H}_{2} \mathrm{O}$ (Sigma). Phosphate solution was prepared from $\mathrm{Na}_{2} \mathrm{HPO}_{4}$ (Unilab). Bromide, sulphate, chloride and nitrate solutions were prepared by dissolving their sodium salts. Industrial wastewater samples containing arsenic ion were obtained from electronic and wood treatment industries. Poly(hydroxamic acid) chelating resin was prepared by reacting poly methylacrylate-divinyl benzene 
with hydroxylamine hydrochloride (BDH) in alkaline medium using method reported elsewhere [7]. Sn-loaded poly(hydroxamic acid) chelating resin (Sn-PHA) was prepared by shaking $15 \mathrm{~g}$ of PHA resin in $200 \mathrm{~cm}^{3}(0.1 \mathrm{M})$ $\mathrm{HCl}$ solution containing of $2.0 \mathrm{~g}$ of $\mathrm{SnCl}_{4}$ for $24 \mathrm{~h}$. The Sn-PHA resin was then filtered and the dry resin was used in the following arsenic sorption studies.

\subsection{Sorption of arsenic by Sn-PHA}

All the sorption equilibrium experiments were conducted batch wise and repeated for three times. The sorption equilibrium was attained by shaking $0.1 \mathrm{~g}$ of Sn-PHA in $20 \mathrm{~cm}^{3}$ aqueous solutions containing $365 \mathrm{mg}$ $\mathrm{dm}^{-3}$ arsenic (V) ions at $100 \mathrm{rpm}$ for a predetermined time period. Initial $\mathrm{pH}$ of the solutions was adjusted to desired $\mathrm{pH}$ by adding hydrochloric acid or sodium hydroxide solutions and measured using $\mathrm{pH}$ meter model Fisher $\mathrm{AB} 15$. Sorption experiments were carried out in a water bath shaker at 25,50 or $90^{\circ} \mathrm{C}$. The solution was then filtered and the metal ion concentrations in the filtrate and the initial sample were measured using a PLASMA 1000 model inductively coupled plasma atomic emission spectrometer (ICP-AES). The sorption capacity, $q$ (mg As/g resin), was calculated from the change in the metal concentration before and after equilibrium and the weight of the dry Sn-PHA resin as follows:

$$
q=\left(C_{o}-C\right) V / W
$$

where $C_{o}$ and $C$ are the initial and equilibrium concentrations of the metal ion in aqueous phase $\left(\mathrm{mg} \mathrm{dm}^{-3}\right), V$ is the volume of the aqueous phase $\left(\mathrm{dm}^{3}\right)$, and $W$ is the dry weight of the Sn-PHA resin $(\mathrm{g})$. Sorption rate was measured by shaking $0.1 \mathrm{~g}$ of the Sn-PHA resin in $20 \mathrm{~cm}^{3}$ of $365 \mathrm{mg} \mathrm{dm}^{-3} \mathrm{As}(\mathrm{V})$ solution for different time period. Sorption isotherm was studied by shaking $0.1 \mathrm{~g}$ of the Sn-PHA resin in $20 \mathrm{~cm}^{3}$ with different concentration of $\mathrm{As}(\mathrm{V})$ for $16 \mathrm{~h}$. Selectivity study was carried out by equilibrating $0.1 \mathrm{~g}$ of Sn-PHA resin in 20 $\mathrm{cm}^{3}$ of $365 \mathrm{mg} \mathrm{dm}^{-3} \mathrm{As}(\mathrm{V})$ solution containing chloride, bromide, nitrate, sulphate or phosphate ions of various concentrations. Removal of arsenic and other ions from industrial wastewater samples was carried out by shaking $0.1 \mathrm{~g}$ of Sn-PHA resin in $20 \mathrm{~cm}^{3}$ of the sample for over night.

\subsection{Effect of $\mathrm{pH}$ on $\mathrm{As}(\mathrm{V})$ sorption by Sn-PHA}

\section{Results and Discussion}

The $\mathrm{pH}$ of a solution is an important parameter in sorption process because of the $\mathrm{pH}$ dependencies of the complexation reactions or electrostatic interactions in physisorption processes at the sorption surface. Since tin could form an amphoteric compound the $\mathrm{pH}$ dependencies of arsenate sorption has to be determined. Thus, the effect of $\mathrm{pH}$ on sorption capacities of the metal anions was examined by varying the initial $\mathrm{pHs}$ of the solutions. Variation of the metal uptake with $\mathrm{pH}$ is shown in Fig. 1. The sorption capacity was found to be low at higher $\mathrm{pH}$ values and increased with decrease in $\mathrm{pH}$. This can be explained with a coulombic force between negative arsenic and the positively charged charge of the Sn on the resin. As the $\mathrm{pH}$ decreased, the sorbent surface becomes more positive and therefore electrostatic attraction between the arsenic anion and Sn-PHA surface is likely to be increased. The optimum $\mathrm{pH}$ values at which the maximum metal uptake could be achieved, was obtained as 2. A similar trend of $\mathrm{pH}$ dependent was reported by other workers for the sorption of $\mathrm{As}(\mathrm{V})$ by hydrous tin oxide [4]. Fig. 1 also shows that the $\mathrm{Sn}$ on PHA is stable at this optimum pH. For all subsequent experiments, this optimum $\mathrm{pH}$ value was used.

\subsection{Sorption kinetics}

Metal ion uptake capacities were determined as a function of time to determine an optimum contact time for the sorption As(V) on Sn-PHA. Fig. 2 shows time course of the sorption equilibrium of $\mathrm{As}(\mathrm{V})$ ion onto $\mathrm{Sn}$ PHA resin. As it can be seen from the figure, the sorption process is rapid in the initial stages of contact time but gradually decreases with time until equilibrium is attained at $20 \mathrm{~h}$. Therefore $20 \mathrm{~h}$ of contact time was chosen as the equilibration time for the experimental studies unless otherwise stated, to ensure that equilibrium condition was achieved. Kinetic characteristic in a chelating polymer depends not only on the presence of active metal site on it but also depends on the accessibility of the metal site without sterical hindrance which is greatly determined by the polymeric matrices. Sorption process is known to be controlled by different kinds of mechanisms such as mass transfer, chemical reactions and particle diffusion. Hence, several sorption models were applied to evaluate the experimental data. For this purpose Lagergren's pseudo-first-order kinetic model, pseudo-second-order kinetic model and intra particle diffusion model were applied.

First-order kinetic: The linearized form of the first-order rate equation by Lagergren [8] is given as

$$
\log \left(q_{e}-q_{t}\right)=\log q_{e}-k_{a d s} \times t / 2.303
$$

where $q_{e}$ and $q_{t}$ are the amount of the arsenic ions sorbed $\left(\mathrm{mg} \mathrm{g}^{-1}\right)$ at equilibrium and at time $t(\mathrm{~min})$, respectively and $k_{a d s}$ is the sorption rate constant $\left(\min ^{-1}\right)$. The plots of $\log \left(q_{e}-q_{t}\right)$ versus $t$ gives a straight line with the equation

$$
y=-0.0024 x+1.37
$$

The value of $k_{a d s}$ can be calculated from the slope while the theoretical capacity $q_{e}$ (theor) can be calculated from the intercept at $y$ axis. In order this model to be applicable, a part from high correlation coefficient value of the plot, the calculated equilibrium sorption capacity value, $q_{e}$ (theor) should be in agreement with the experimental 


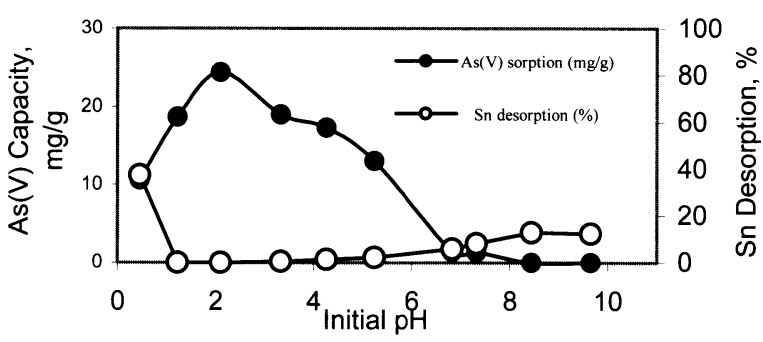

Fig. 1. The effect of $\mathrm{pH}$ on the sorption of $\mathrm{As}(\mathrm{V})$ by $\mathrm{Sn}-\mathrm{PHA}$ resin. Initial $\mathrm{As}(\mathrm{V}) \mathrm{mg} \mathrm{dm}^{-3}$; volume 20 $\mathrm{cm}^{3}$; sorbent dosage $0.1 \mathrm{~g}$; $\mathrm{t}: 20 \mathrm{~h}$; temperature $25^{\circ} \mathrm{C}$

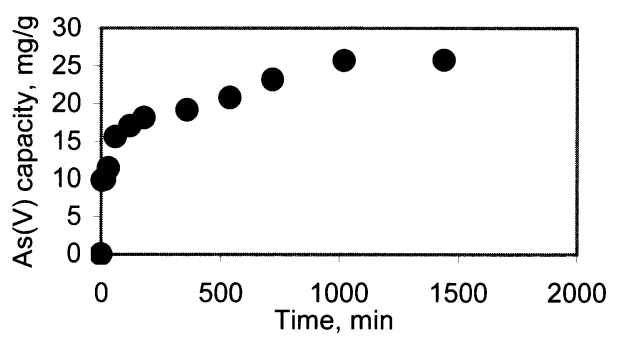

Fig. 2. Sorption rates of $\mathrm{As}(\mathrm{V})$ ions onto Sn-PHA resin. Initial As(V) $365 \mathrm{mg} \mathrm{dm}^{-3}$; volume $20 \mathrm{~cm}^{3} ; \mathrm{pH}$ 2; sorbent dosage $0.1 \mathrm{~g}$; temperature $25^{\circ}$

$q_{e}(\exp )$ value [9]. Experimental and theoretically calculated $q_{e}$ values and the correlation coefficient of the plot $\left(R^{2}\right)$ are given in Table 1. As it can be seen the linear correlation coefficient of the plots using first order kinetic model is not good and experimental and calculated $q_{e}$ values are not in agreement with each other. So, the result suggests that the sorption of $\mathrm{As}(\mathrm{V})$ by Sn-PHA resin is not a first-order reaction.

Table 1 First-order, second-order and intraparticle diffusion rate constants of As(V) sorption by Sn-PHA resin. First-order rate equation $\quad$ Second-order rate equation Intraparticle diffusion

\begin{tabular}{cccccccc|c}
$\begin{array}{c}q_{e}(\exp ) \\
\left(\mathrm{mg} \mathrm{g}^{-1}\right)\end{array}$ & $\begin{array}{c}k_{a d s} \\
\left(\mathrm{~min}^{-1}\right)\end{array}$ & $\begin{array}{c}q_{e}(\text { theor }) \\
\left(\mathrm{mg} \mathrm{g}^{-1}\right)\end{array}$ & $R^{2}$ & $\begin{array}{c}k_{2} \\
\left(\mathrm{~g} \mathrm{mg}^{-1} \mathrm{~min}^{-1}\right)\end{array}$ & $\begin{array}{c}q_{e}(\text { theor }) \\
\left(\mathrm{mg} \mathrm{g}^{-1}\right)\end{array}$ & $R^{2}$ & \multicolumn{2}{c}{$\begin{array}{c}\text { rate equation } \\
k_{\text {id }} \\
\left(\mathrm{mg} \mathrm{g}^{-1} \mathrm{~min}^{-1 / 2}\right)\end{array}$} \\
\hline \hline 25.80 & 0.0055 & 23.37 & 0.88 & 0.00065 & 26.18 & 0.99 & 0.52 & 0.99 \\
\hline
\end{tabular}

Second-order Kinetics: Experimental data were also applied to the pseudo-second order kinetic model whose equation can be written as below:

$$
t / q_{t}=1 / k_{2} q_{e}^{2}+t / q_{e}
$$

where $k_{2}\left(\mathrm{~g} \mathrm{mg}^{-1} \mathrm{~min}^{-1}\right)$ is the rate constant of pseudo-second order sorption reaction. Second-order kinetic is applicable if the plot of $t / q_{t}$ versus $t$ shows linearity and the value of $q_{e}$ calculated close to experimental. Also this procedure is more likely to predict the behavior over whole range of sorption and is in agreement with chemical sorption being the rate-controlling step [10]. The plots of $t / q_{t}$ versus $t$ give a straight line (not shown) with the equation

$$
y=0.0382 x+2.25
$$

The rate constants $\left(k_{2}\right)$, correlation coefficients of the plots together with the theoretical $q_{e}$ values are given in Table 1. It is clear from these results that the correlation coefficient is high and experimental and theoretical $q_{e}$ values are in accordance with each other. These results suggest that the sorption of As(V) on Sn-PHA follows the second-order type kinetic reaction [4]. This result can be expected because the ordinary type of exchange processes are more rapid and controlled mainly by diffusion, whereas, those in a chelating exchanger is slower and controlled either by particle diffusion mechanism or by a second-order chemical reaction [11]. Sn-PHA with its polymeric porous structure and $\mathrm{Sn}(\mathrm{IV})$ as active ion present on its surface most probably behaves like a chelating exchanger. Therefore second-order chemical reaction kinetics is expected to be followed in the sorption processes.

Intraparticle diffusion: Intraparticle diffusion model is expressed with the equation given by Weber and Morris [12]:

$$
q_{t}=k_{i d} t^{1 / 2}
$$

where $q_{t}$ is the amount of metal ions adsorbed at time $t\left(\mathrm{mg} \mathrm{g}^{-1}\right)$ and $k_{i d}$ is the intraparticle diffusion rate constant $\left(\mathrm{mg} \mathrm{g}^{-1} \mathrm{~min}^{-1 / 2}\right)$. Plots of $q_{t}$ versus $t^{1 / 2}$ are shown in Fig. 3. As it can be seen, there is no linear distribution of the points. The plot has an initial curve portion followed by a linear line and a plateau. Initial curved portion represents the bulk diffusion or exterior sorption rate which is very high, the subsequent linear portion is attributed to the intraparticle diffusion and plateau portion represents the equilibrium. The intraparticle diffusion constant was calculated from the slope of the linear portions of the curves and given in Table 1. The result showed that intraparticle diffusion, which may play an important role as a rate determining step in the sorption process, was observed to be effective. However, because of the deviation of the curves from the origin and non linear distribution of the plots, intraparticle diffusion cannot be accepted as the only rate determining step for the sorption of $\mathrm{As}(\mathrm{V})$ onto Sn-PHA resin [13]. 


\subsection{Sorption isotherms}

The effect of initial concentrations on $\mathrm{As}(\mathrm{V})$ uptake was investigated by varying the initial concentrations of the arsenic anion at optimum $\mathrm{pH}$ value and $20 \mathrm{~h}$ of equilibration time. As it can be seen from Fig. 4 that, the sorption capacities were increased with increasing the initial concentrations and reached a plateau showing the maximum sorption capacity of resin. The increase in loading capacity of the sorbent with relation to the $\operatorname{As}(\mathrm{V})$ concentration can be explained with the high driving force for mass transfer. The analysis of the isotherm data is important to develop an equation which accurately represents the results and which could be used for design purposes [14]. The experimental data obtained from the effect of initial concentration on sorption capacity were evaluated with the three sorption models which are Langmuir, Freundlich and D-R models. The linearized forms of the equations representing the models were used.

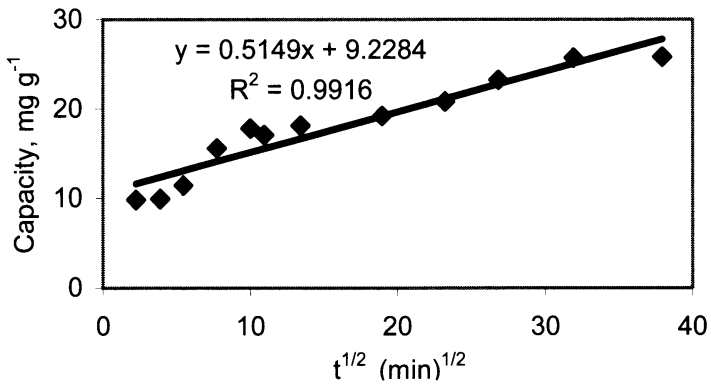

Fig. 3. Intraparticle diffusion plots for $\mathrm{As}(\mathrm{V})$ on $\mathrm{Sn}-$ PHA resin. Initial As(V) $365 \mathrm{mg} \mathrm{dm}^{-3}$; volume 20 $\mathrm{cm}^{3} ; \mathrm{pH} 2$; sorbent dosage $0.1 \mathrm{~g}$; temperature $25^{\circ} \mathrm{C}$

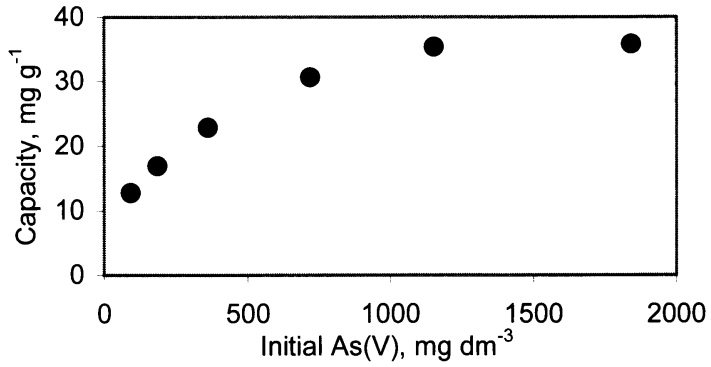

Fig. 4. Effect of initial concentration on $\mathrm{As}(\mathrm{V})$ sorption on Sn-PHA. Volume $20 \mathrm{~cm}^{3} ; \mathrm{pH} 2$; sorbent dosage $0.1 \mathrm{~g}$; temperature $25^{\circ} \mathrm{C}$

Langmuir isotherm: Langmuir isotherm which models the monolayer coverage of the sorption surface assumes that sorption occurs at specific homogeneous sorption sites within the sorbent and intermolecular forces decrease rapidly with the distance from the sorption surface. The model also based on the assumption that all the sorption sites are energetically identical and sorption occurs on a structurally homogeneous sorbent. Linearized form of the Langmuir equation based on those assumptions is given as [15]:

$$
C_{e} / q_{e}=1 / b Q^{\circ}+C_{e} / Q^{\circ}
$$

where $q_{e}$ is the amount of solute sorbed on the surface of the sorbent $\left(\mathrm{mg} \mathrm{g}^{-1}\right), C_{e}$ is the equilibrium $\mathrm{As}(\mathrm{V})$ concentration in the solution $\left(\mathrm{mg} \mathrm{dm}{ }^{-3}\right), Q^{\circ}$ is the maximum sorption capacity at monolayer coverage $\left(\mathrm{mg} \mathrm{g}^{-1}\right)$ and $b$ is the Langmuir sorption constant which relate to binding constant $\left(\mathrm{dm}^{3} \mathrm{mg}^{-1}\right)$. The plots of $C_{e} / q_{e}$ versus $C_{e}$ give a straight line with the equation:

$$
y=0.026 x+3.121
$$

and the values of $Q^{\circ}$ and $b$ can be calculated from the slope and the intercept of the plots, respectively. Langmuir constants and correlation coefficients $\left(R^{2}\right)$ are given in Table 2 .

Freundlich isotherm: Freundlich equation is derived to model the multilayer sorption on heterogeneous surfaces. The Freundlich model is formulated as [4]:

$$
q_{e}=K_{F} C_{e}^{1 / n}
$$

where $q_{e}$ is the equilibrium solute concentration on the sorbent $\left(\mathrm{mg} \mathrm{g}^{-1}\right), C_{e}$ is the equilibrium concentration of the solute $\left(\mathrm{mg} \mathrm{dm}^{-3}\right), K_{F}$ is the Freundlich constant $\left(\mathrm{mg} \mathrm{g}^{-1}\right)$ which indicates the sorption capacity and $n$ is the heterogeneity factor which represents the bond distribution. A linear form of the Freundlich equation can be obtained by taking logarithms of the equation:

$$
\log q_{e}=\log K_{F}+1 / n \log C_{e}
$$

According to this equation the plot of the $\log q_{e}$ versus $\log C_{e}$ gives a straight line and $K_{F}$ and $n$ values can be calculated from the intercept and slope of this straight line, respectively. Experimental data obtained from the effect of initial concentrations to the sorption of $\mathrm{As}(\mathrm{V})$ on Sn-PHA was evaluated by applying this equation and the plots of $\log q_{e}$ versus $\log C_{e}$ give a straight line with the equation:

$$
y=0.28 x+0.685
$$

and the calculated related constants are given in Table 2. On the comparison of the $R^{2}$ values given in Table 2, we can conclude that Langmuir equation represents a better fit to the experimental data than the Freundich equation. This result also predicts the homogenity of the sorption sites on Sn-PHA. The Langmuir constant $Q^{\circ}$ indicates the maximum sorption capacity of the sorbent. As it can be seen from Table $2, Q^{\circ}$ value for $\mathrm{As}(\mathrm{V})$ sorption was found to be $38.46 \mathrm{mg} \mathrm{g}^{-1}\left(0.51 \mathrm{mmol} \mathrm{g}^{-1}\right)$. This sorption capacity is comparable with some of those reported metal loaded types of sorbent [16-20] but very much higher compared to the sorption by hydrous tin 
oxide [4]. The Langmuir constant $b$, which indicate the binding constant for As(V) sorption on Sn-PHA, was found to be $6.09 \mathrm{dm}^{3} \mathrm{mmol}^{-1}$.

Table 2. Langmuir, Freundlich and D-R isotherm constants of As(V) sorption by Sn-PHA

\begin{tabular}{ccccccc}
\hline \multicolumn{2}{c}{ Langmuir isotherm } & \multicolumn{5}{c}{ D-R isotherm } \\
$Q^{\circ}\left(\mathrm{mg} \mathrm{g}^{-1}\right)$ & $b\left(\mathrm{dm}^{3} \mathrm{mg}^{-1}\right)$ & $R^{2}$ & $q_{m}\left(\mathrm{mg} \mathrm{g}^{-1}\right)$ & $k\left(\mathrm{~mol}^{2} \mathrm{~kJ}^{-2}\right)$ & $E\left(\mathrm{~kJ} \mathrm{~mol}^{-1}\right)$ & $R^{2}$ \\
\hline \hline 38.46 & $8.11 \times 10^{-2}$ & 0.996 & 52.26 & $4.0 \times 10^{-9}$ & 11.18 & 0.980 \\
$\left(0.51 \mathrm{mmol} \mathrm{g}^{-1}\right)$ & $\left(6.09 \mathrm{dm}^{3} \mathrm{mmol}^{-1}\right)$ & & $\left(0.69 \mathrm{mmol} \mathrm{g}^{-1}\right)$ & & & \\
\hline
\end{tabular}

\begin{tabular}{ccc}
\hline \multicolumn{3}{c}{ Freundlich isotherm } \\
$K_{\mathrm{F}}\left(\mathrm{mg} \mathrm{g}^{-1}\right)$ & $n$ & $R^{2}$ \\
\hline \hline 4.84 & 3.57 & 0.983 \\
\hline
\end{tabular}

$D-R$ isotherms: Langmuir and Freundlich isotherms do not give any idea about sorption mechanism but the former describes sorption on a single type of uniform pores. In this respect the D-R isotherm is an analogue of Langmuir type but it is more general because it does not assume a homogeneous surface or constant sorption potential [21]. The linearized D-R isotherm equation can be written as:

$$
\ln q=\ln q_{m}-k \varepsilon^{2}
$$

where $\varepsilon$ (Polanyi potential) is $[R T \ln (1+(1 / C \mathrm{e}))], q$ is the amount of solute adsorbed per unit weight of sorbent $\left(\mathrm{mol} \mathrm{g}{ }^{-1}\right), k$ is a constant related to the sorption energy $\left(\mathrm{mol}^{2} \mathrm{~kJ}^{-2}\right)$ and $q_{m}$ is the sorption capacity $\left(\mathrm{mol} \mathrm{g}^{-1}\right)$. The plots of $\ln q$ versus $\varepsilon^{2}$ (not shown) give a straight line curve with the equation:

$$
y=-4.0 \times 10^{-9} x-7.27
$$

The values of $q_{\mathrm{m}}$ and $k$ were calculated from the intercept and slope of the straight line and presented in Table 2 . The free energy of sorption, $E\left(\mathrm{~kJ} \mathrm{~mol}^{-1}\right)$ was calculated from the $k$ values using the equation:

$$
E=(-2 k)^{-0.5} \quad(14)
$$

The magnitude of free energy $E$ is useful for estimating the type of sorption process. The free energy between 8 and $16 \mathrm{~kJ} \mathrm{~mol}^{-1}$ indicates sorption process can be explained by ion exchange process [21]. In this study the $E$ value is calculated to be $11.18 \mathrm{~kJ} \mathrm{~mol}^{-1}$. Therefore it is possible to say that sorption mechanism of As(V) on $\mathrm{Sn}$ PHA can be explained with an ion-exchange process [4].

\subsection{Thermodynamics of the sorption}

The experiment on the effect of temperature on sorption of $\mathrm{As}(\mathrm{V})$ onto Sn-PHA resin was carried out at $25,40,60,75$ and $90^{\circ} \mathrm{C}$. The initial concentrations of $\mathrm{As}(\mathrm{V})$ was taken as $365 \mathrm{mg} \mathrm{dm}^{-3}$. It was observed that the distribution coefficient values, $K_{\mathrm{D}}$, increased with increase in temperature and that shows the endothermic nature of the sorption. Thermodynamic parameters like Gibs's free energy change $\left(\Delta G^{\circ}\right)$, enthalpy change $\left(\Delta H^{\circ}\right)$, and entropy change $\left(\Delta S^{\circ}\right)$ were estimated using the following equations:

$$
\begin{aligned}
& \log K_{D}=\Delta S^{\circ} / 2.303 R-\Delta H^{\circ} / 2.303 R T \\
& \Delta G^{o}=\Delta H^{o}-T \Delta S^{\circ}
\end{aligned}
$$

where $K_{\mathrm{D}}$ is the distribution coefficient $\left(\mathrm{cm}^{3} \mathrm{~g}^{-1}\right)$, and $R$ is gas constant $\left(8.3145 \mathrm{~kJ} \mathrm{~mol}^{-1} \mathrm{~K}^{-1}\right)$. Using equation (15) the values of $\Delta H^{\circ}$ and $\Delta S^{\circ}$ were calculated from the slope and intercept of the $\log K_{\mathrm{D}}$ versus $1 / T$ plots (not shown) which give a straight line $\left(R^{2}=0.97\right)$ with the equation

$$
y=0.27 x+2.55
$$

and listed in Table 3. The $\Delta H^{\circ}$ value was found to be $5.20 \mathrm{~kJ} \mathrm{~mol}^{-1}$. The positive value of $\Delta H^{0}$ confirms to endothermic nature of the sorption. The $\Delta G^{0}$ values were calculated at different temperatures using equation (16) and listed in Table 3. Negative values of $\Delta G^{\mathrm{o}}$ indicates the spontaneous nature of the reaction, which is favored and getting easier at higher temperatures. The value of $\Delta S^{\circ}$ was found to be positive due to the exchange of the metal ions with more mobile ions present on the exchanger. In the case of physisorption which may also contribute to the total sorption process can cause increase in entropy because the release of the water molecules from the hydrated ions and from the surface of the sorbent.

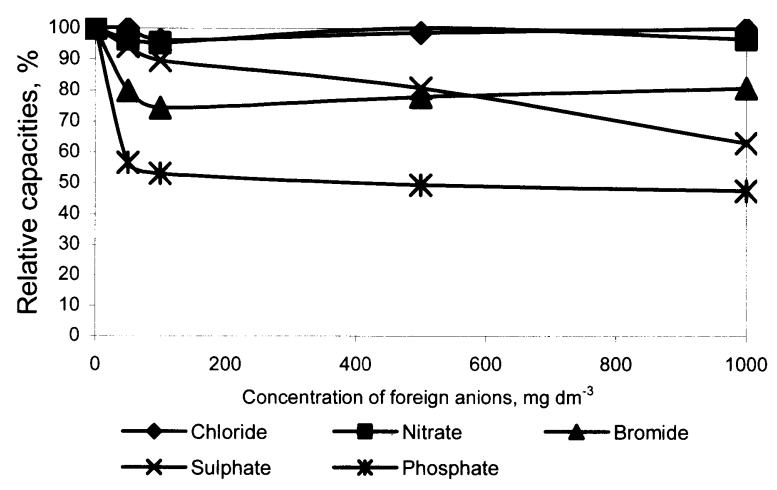

Fig. 5 Selectivity of Sn-PHA resin for sorption of $\mathrm{As}(\mathrm{V})$ in the presence of various competing ions. 


\subsection{Sorption selectivity of Sn-PHA for arsenate}

In many cases samples such as industrial wastewater contains various kinds of ions which are not necessary to be removed. It is therefore required for a sorbent to have a high selectivity only toward hazardous ion to prolong it's life. Fig. 5 shows the sorption behavior of Sn-PHA resin for arsenate in the presence of common anions. The figure shows that phosphate, sulphate and bromide ions reduced the arsenic sorption capacity while nitrate and chloride did not affect the arsenic removal significantly.

\subsection{Removal of arsenate ion from industrial wastewater}

The ability of the Sn-PHA resin to remove arsenic ion was tested to two types of industrial waste water samples namely (A) semiconductor and (B) wood treatment industries. The removal is effective with more than $80 \%$ of the arsenic from the samples was removed by the resin (Table 4). The percentages of arsenic removal from wastewater samples were higher for lower concentrations samples. As expected, a quantitative removal was not possible due to the presence of sulphate in the wastewater from wood treatment and sulphate and phosphate in the wastewater from semiconductor industries.

Table 3 Thermodynamic properties of As(V) sorption onto Sn-PHA

\begin{tabular}{ccccc}
\hline $\begin{array}{c}\mathrm{Tem} \\
{ }^{\circ} \mathrm{C}\end{array}$ & $\begin{array}{c}K_{d} \\
\mathrm{dm}^{3} \mathrm{~g}^{-1}\end{array}$ & $\begin{array}{c}\Delta G^{\mathrm{o}} \\
\mathrm{kJ} \mathrm{mol}^{-1}\end{array}$ & $\begin{array}{c}\Delta H^{\mathrm{o}} \\
\mathrm{kJ} \mathrm{mol}^{-1}\end{array}$ & $\begin{array}{c}\Delta S^{\mathrm{O}} \\
\mathrm{J} \mathrm{mol}^{-1}\end{array}$ \\
\hline 25.0 & 87 & -11.05 & 5.20 & 54.55 \\
40.0 & 93 & -11.87 & & \\
60.0 & 110 & -12.96 & & \\
75.0 & 120 & -13.78 & & \\
90.0 & 123 & -14.59 & & \\
\hline
\end{tabular}

Table 4 Evalution of Sn-PHA resin for arsenic removal from industrial wastewater

\begin{tabular}{|c|c|c|c|}
\hline \multirow[t]{2}{*}{ Sample } & \multicolumn{2}{|c|}{$\mathrm{As}(\mathrm{V})$ concentration $\left(\mathrm{mg} \mathrm{dm}^{-3}\right)$} & \multirow{2}{*}{$\underset{\%}{\text { Removal }}$} \\
\hline & Initial & Final & \\
\hline A1 & 18.24 & 0.54 & 97.0 \\
\hline $\mathrm{A} 2$ & 36.57 & 3.65 & 90.0 \\
\hline A3 & 76.68 & 12.25 & 84.0 \\
\hline B1 & 54.63 & 6.33 & 88.4 \\
\hline $\mathrm{B} 2$ & 27.63 & 2.21 & 92.0 \\
\hline B3 & 11.20 & 0.63 & 94.4 \\
\hline
\end{tabular}

\section{Acknowledgement}

This study was supported by the Ministry of Science, Technology and Innovation, Malaysia under IRPA project.

\section{References}

1) G. T. Spiro and W. M. Stigliani, "Chemistry of the Environment”, Prentice-Hall, New Jersey, (2003) Part III, p.p. 191-252.

2) D. J. Vaughan, Elements, 2, 71-75 (2006).

3) D. Mohan, and C. U. Pittman Jr., J. Hazard. Mater., 142, 1-53 (2007).

4) B. Manna, and U. C. Ghosh, J. Hazard. Mater., (2006) imprint.

5) T. M. Suzuki, J. O. Bomani, H. Matsunaga, and T. Yakoyama, React. Funct. Polym., 43, 165-172 (2000).

6) W. M. Z. Wan Yunus, and M. J. Haron, Proc. Malaysian Chem. Conf., (Eds. M.M. Singh and B.K. Ong), IKM, K. Lumpur (1989) p.p. 275-281.

7) M. J. Haron, W. M. Z. Wan.Yunus, M. Z. Desa, and A. Kassim, Talanta, 41, 805-807 (1994).

8) N. Unlu, and M. Ersoz, Separation and Purification Technology, 52, 461-469 (2007).

9) M. Ozacar, and Y. A. Sengil, J. Hazard. Mater., B 98, 211-224 (2003).

10) M. Docgan, M. Alkan, A. Turkyylmaz, and Y. Ozdemir, J. Hazard. Mater., B 109, 141-148 (2004).

11) G. Kantipuly, S. Katragadda, A. Chow, and H. D. Gesser, Talanta, 37, 491-517, (1990).

12) W. J. Weber and J. C. Morris, “Advances in Water Pollution Research”, Pergamon Press, N.Y. (1962), pp. 231-266.

13) C. K. Jain, and K. Sharma, Water Air Soil Pollut., 137, 1-19 (2002).

14) D. Ozkan, M. Alkan, and M. Docgan, Sorption, 8, 341-349 (2002).

15) D. Zhao, A. K. SenGupta, and Y. Zhu, Ind. Eng.Chem. Res., 34, 2676-2684 (1995).

16) M. Chanda, K. F. O’Driscoll, and G. L. Rempel, Reactive Polym., 8, 85-95 (1988).

17) H. Matsunaga, T. Yokoyama, R. J. Eldridge, and B. A. Bolto, Reac. Func. Polym., 29, 167-174 (1996).

18) M. J. Haron, W. M. Z. Wan Yunus, M. A. Sukari, L. T. Wum, and S. Tokunaga. Malaysian J. Anal. Sci., 3, 194-204 (1997).

19) M. J. Haron, W. M. Z. Wan Yunus, N. L. Yong, and S. Tokunaga, Chemosphere, 39, 2459-2466 (1999).

20) M. J. Haron, W. M. Z. Wan Yunus, S. H. Salleh, and Y. M. Ahmed, "Ion Exchange” (Ed. M. Cox), Information Press, U.K. (2004) pp. 117-125.

21) A. Kilislioglu, and B. Bilgin, Appl. Radiat. Isotopes, 50, 155-160 (2003). 